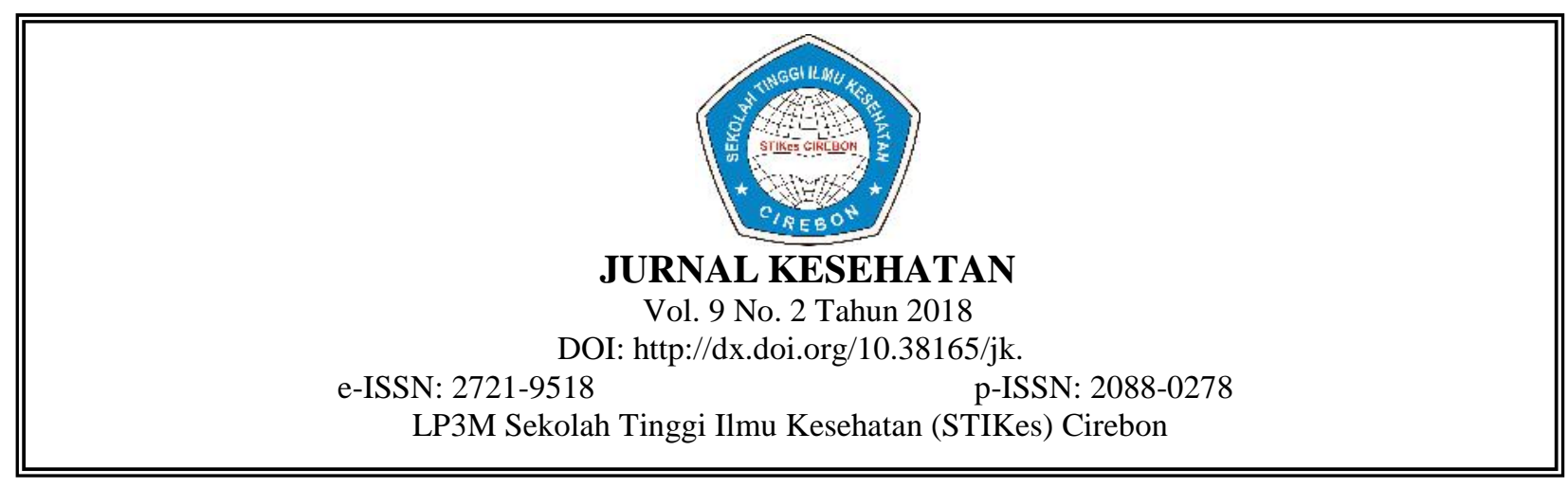

\title{
HUBUNGAN CEDERA KEPALA DENGAN DISORIENTASI PADA PASIEN KECELAKAAN LALU LINTAS
}

\author{
Nuniek Tri Wahyuni* \\ Program Studi Ilmu Keperawatan, Sekolah Tinggi Ilmu Kesehatan Cirebon \\ nuniek.triwahyuni@yahoo.com \\ Winda Indahsari ** \\ Program Studi Ilmu Keperawatan, Sekolah Tinggi Ilmu Kesehatan Cirebon
}

\begin{abstract}
Abstrak
Banyak hal yang menjadi penyebab terjadinya cedera kepala, salah satu penyebab terjadinya cedera kepala yang serius adalah kecelakaan lalu lintas (sekitar 60\% kematian yang disebabkan kecelakaan lalu lintas merupakan akibat cedera kepala). Tujuan penelitian ini utuk mengidentifikasi cedera kepala dengan disorientasi pada pasien kecelakaan lalu lintas di IGD RSD Gunung Jati Kota Cirebon tahun 2018. Jenis penelitian yang digunakan dalam penelitian ini adalah studi kolerasi yang bersifat deskriptif, dengan menggunakan pendekatan cross sectional. Populasi dalam penelitian ini adalah pasien cedera kepala di RSD Gunung Jati Kota Cirebon, teknik pengambilan sampel menggunakan accidental sampling dengan jumlah sampel 22 responden. Teknik pengumpulan data menggunakan lembar observasi penilaian GCS dan lembar kuesioner TOAG. Analisis bivariat menggunakan uji chi square. Hasil penelitian ini menunjukan bahwa sebagian besar cedera kepala ringan yaitu sebanyak 16 dari 22 responden atau sekitar (72.7\%) dan sebagaian besar mengalami disorientasi sedang, yaitu sebanyak 14 orang dari 22 responden atau sekitar $(63,6 \%)$. Berdasarkan analisa statistik uji Spearman's Rho menunjukan bahwa terdapat hubungan cedera kepala dengan disorientasi pada pasien kecelakaan lalu lintas di IGD RSD Gunung Jati Kota Cirebon serta nilai probabilitas ( $\mathrm{p}=0.001)$.
\end{abstract}

Kata Kunci: Cedera Kepala, Disorientasi

\begin{abstract}
Many of the causes of head injury, one of the causes of serious head injuries are traffic accidents (about $60 \%$ of deaths caused by traffic accidents are the result of head injury). The purpose of this study was to identify head injury with disorientation in traffic accident patients at IGD RSD Gunung Jati Kota Cirebon 2018. The type of research used in this study is a descriptive correlation study, using a cross sectional approach. The population in this study were head injury patients at IGD RSD Gunung Jati Kota Cirebon, the sampling technique used was accidental sampling with a sample of 22 respondents. Data collection techniques used the GCS assessment sheet and TOAG questionnaire sheet. Bivariate analysis using the chi square test.

The results of this study indicate that, which is mostly light weight that is as much as 16 out of 22 respondents or approximately (72.7\%) and most of moderate disorientation, which is as many as 14 people from 22 respondents or approximately (63.6\%).Based on statistical analysis Spearman's Rho showed that there was correlation with the patient in RSD Teachers Mountain Jati Cirebon City and probability value $(p=0,001)$.
\end{abstract}

Keywords: Head Injury, Disorientation 


\section{PENDAHULUAN}

Kecelakaan lalu lintas merupakan penyebab utama kematian dengan berbagai sebab, menempati urutan kesepuluh penyebab semua kematian dan bulan pertama kesembilan sebagai kontributor utama kematian global. Kejadian kecelakaan lalu lintas meningkat dalam jumlah maupun jenisnya dengan perkiraan angka kematian dari 5,1 juta pada tahun 1990 menjadi 8,4 juta pada tahun 2020 atau meningkat sebanyak $65 \%$. Kecelakaan lalu lintas dapat mengakibatkan berbagai cedera. Cedera yang paling banyak terjadi pada saat kecelakaan lalu lintas adalah cedera kepala.

Menurut World Health Organization (WHO) Tahun 2008, kecelakaan lalu lintas menjadi penyebab kematian ke-10 di dunia dengan jumlah kematian 1,21 juta $(2,1 \%)$ dan menurut profil Kesehatan Indonesia tahun 2008 cedera merupakan penyebab kematian utama keempat (6,5\%) untuk semua umur setelah stroke, Tubercolosis, dan hipertensi. ${ }^{2}$

Menurut riset kesehatan daerah Departemen Kesehatan Republik Indonesia 2013, dalam laporannya mendapatkan bahwa di Indonesia, setiap 1000 orang diantaranya mengalami cedera kepala. Cedera kepala merupakan penyebab ke tiga kematian pada semua umur, dengan proposi bagian tubuh yang terkenan cedera 14,9\%. Dari kasus kecelakaan lalu lintas 6 orang mengalami cedera di Indonesia, 1 orang diantaranya mengalami cedera kepala. ${ }^{3}$

Berdasarkan diagnosa Nakes maupun diagnosis, Provinsi Jawa Barat pada tahun 2007 mengalami cedera akibat kecelakaan lalu lintas $8.5 \%$ yaitu sebanyak 84.774 orang. Kecenderungan prevelensi cedera di Jawa Barat $10.0 \%$ pada tahun 2013. Menurut Kabupaten/ Kota prevelensi Cirebon dengan kasus cedera kepala akibat kecelakaan lalu lintas pada tahun 2011 yaitu 19,2\%. ${ }^{4}$

Orang yang mengalami cedera kepala akan mengalami disorientasi karena adanya kerusakan jaringan yang menyebabkan gangguan fungsi neurologik seperti komusio serebri (gegar otak), kontusio serebri (memar), laserasio serebri dan akan terjadi disorientasi yang menyangkut waktu, tempat, dan identitas orang. Lamanya disorientasi retrograde biasanya akan menurun secara progresif sedangkan anterograde suatu defisit dalam membentuk memori baru setelah sembuh dari disorientasi.

Berdasarkan sudi pendahuluan di IGD Rumah Sakit Tk. 11l 03.06.01 Ciremai dan di IGD RSD Gunung Jati Kota Cirebon didapatkan data pasien cedera kepala dari September sampai November 2017, yaitu 5 pasien di IGD Rumah Sakit Tk. 111 03.06.01 Ciremai dan di IGD RSD Gunung Jati Kota Cirebon diperoleh jumlah pasien cedera kepala yaitu 121 pasien. ${ }^{5}$ Tujuan penelitian adalah untuk mengetahui hubungancederakepaladengan disorientasipada pasien kecelakaan lalu lintasdi RSD Gunung Jati Kota Cirebon Tahun 2018.

\section{METODE PENELITIAN}

Metode penelitian ini adalah kolerasi yang bersifat deskriptif, dengan menggunakan pendekatan crossectional. $^{6}$ Populasi dalam penelitian ini adalah semua pasien cedera kepala di IGD RSD Gunung Jati Kota Cirebon. Jumlah diambil dari 26 Maret - 26 April 2018 pasien yang mengalami cedera kepala 22 di IGD RSD Gunung Jati Kota Cirebon.Teknik pengambilan sampel menggunakan accidental sampling. Teknik pengumpulan data menggunakan lembar observasi penilaian GCS dan lembar kuesioner TOAG. Analisis bivariat yang digunakan yaitu uji chi square. Dalam penelitian ini variabel univariat adalah cedera kepala dan disorientasi, data disajikan dalam bentuk frekuensi dan persentase. Analisis bivariat yang dilakukan terhadap dua variabel yang berhubungan atau berkorelasi. 


\section{Cedera Kepala Pada Pasien Kecelakaan Lalu Lintas di RSD Gunung Jati Kota Cirebon}

Tabel 1. Distribusi Frekuensi Responden Berdasarkan Cedera Kepala pada Pasien Kecelakaan Lalu Lintas di RSD Gunung Jati Kota Cirebon

\begin{tabular}{ccc}
\hline Cedera Kepala & Frekuensi & Persentase $(\%)$ \\
\hline Ringan & 16 & 72.7 \\
Sedang & 6 & 27.3 \\
Berat & 0 & 0 \\
\hline Jumlah & 22 & 100 \\
\hline
\end{tabular}

Pada tabel 1. diketahui bahwa hampir sebagian besar pasien kecelakaan lalu lintas cedera kepala di RSD Gunung Jati Kota Cirebon yaitu cedera kepala ringan sebanyak 16 responden $(72,7 \%)$, cedera kepala sedang 6 responden $(27,3 \%)$, cedera kepala berat 0 responden $(0 \%)$.

\section{Disorientasi pada Pasien Kecelakaan Lalu Lintas di RSD Gunung Jati Kota Cirebon}

Tabel 2. Distribusi Frekuensi Responden Berdasarkan Disorientasi pada Pasien Kecelakaan Lalu Lintas Di RSD Gunung Jati Kota Cirebon

\begin{tabular}{rcc}
\hline Disorientasi & Frekuensi & Persentase $(\%)$ \\
\hline Ringan & 7 & 31.8 \\
Sedang & 14 & 63.6 \\
Berat & 1 & 4.5 \\
\hline Jumlah & 22 & 100
\end{tabular}

Pada Tabel 2. diketahui bahwa hampir sebagian besar pasien kecelakaan lalu lintas cedera kepala di RSD Gunung Jati Kota Cirebon mengalami disorientasi sedang sebanyak 14 orang dari 22 responden $(63,6 \%)$.

\section{Hubungan Cedera Kepala dengan Disorientasi Pada Pasien Kecelakaan Lalu Lintas}

Tabel 3. Tabulasi Silang Hubungan Cedera Kepala Dengan Disorientasi Pada Pasien Kecelakaan Lalu Lintas di RSD Gunung Jati Kota

\begin{tabular}{ccccccc}
\hline \multirow{2}{*}{ Cedera Kepala } & \multicolumn{3}{c}{ Disorientasi } & \multirow{2}{*}{ Total } & \multirow{2}{*}{ Pvalue } \\
\cline { 2 - 4 } & Ringan & Sedang & Berat & & 16 & \\
Ringan & 2 & 13 & 1 & 6 & 0,001 \\
Sedang & 5 & 1 & 0 & 0 & \\
Berat & 0 & 0 & 0 & & \\
\hline Total & 7 & 14 & 1 & 22
\end{tabular}

Berdasarkan tabel 3. Didapatkan menunjukkan hasil dimana didapat nilai $\mathrm{p}=0,001$ ( $\mathrm{p}$ $<0,05)$. Hal ini menyimpulkan bahwa hipotesis nul $\left(\mathrm{H}_{\mathrm{o}}\right)$ ditolak atau menunjukkan ada hubungan antara cedera kepala dengan disorientasi pada pasien kecelakaan lalu lintas di RSD Gunung Jati Kota Cirebon Tahun 2018.

\section{PEMBAHASAN}

\section{Cedera Kepala pada Pasien Kecelakaan Lalu Lintas di RSD Gunung Jati Kota Cirebon}

Sebagian besar pasien kecelakaan lalu lintas cedera kepala di RSD Gunung Jati Kota Cirebon yaitu mengalami cedera kepala ringan. Setidaknya semakin banyak tanda dan gejala yang 
ditemukan pada responden tentang tanda dan gejala cedera kepala, maka akan semakin tinggi juga resiko disorientasi yang dialami oleh pasien/responden.

Banyak hal yang menjadi penyebab terjadinya cedera kepala, salah satu penyebab terjadinya cedera kepala yang serius adalah kecelakaan lalu lintas (sekitar 60\% kematian yang disebabkan kecelakaan lalu lintas merupakan akibat cedera kepala).Selain kecelakaan lalu lintas, penyebab cedera kepala disebabkan oleh jatuh, trauma benda tumpul, kecelakaan kerja, kecelakaan rumah tangga, kecelakaan olahraga, trauma tembak dan pecahan bom. ${ }^{8}$

Oleh sebab itu diharapkan kepada responden yang mengalami kecelakaan lalu lintas untuk mentaati peraturan lalu lintas untuk mencegah terjadinya kecelakaan lalu lintas seperti memakai helm dan alat keamanaan lain saat berkendara, serta fokus saat berkendara tidak dalam keadaan mengantuk atau sedang tidak sehat, dan jika sudah mengalami kecelakaan lalau lintas sebaiknya responden lebih mengingkatkan kesadaran diri untuk menjaga keamanan dan keselamatan saat berkendara agar tidak terjadi cedera kepala.

\section{Disorientasi pada Pasien Kecelakaan Lalu Lintas Di RSD Gunung Jati Kota Cirebon}

Pasien kecelakaan lalu lintas yang mengalami cedera kepala di RSD Gunung Jati Kota Cirebon, ternyata sebagian besar mengalami disorientasi sedang, yaitu sebanyak 14 orang dari 22 responden atau sekitar (63,6\%). Disorientasi adalah gangguan orientasi akibat gangguan kesadaran yang dapat menyangkut waktu (tidak tahu-menahu tentang jam, hari, bulan dan tahun), tempat (tidak tahu-menahu dimana dia berada), atau orang (tentang dirinya sendiri atau orang lain, tidak tahu identitasnya atau salah menafsirkan identitas orang lain). ${ }^{4}$ Beberapa teknik pemeriksaan klinis yang biasa dilakukan untuk mempermudah mengetahui apakah pasien mengalami disorientasi atau tidak, cara yang pertama yaitu dengan melihat orientasi tempat dan waktu, apakah pasien bisa mengatakan jam, hari, bulan dan tahun, saat ini secara benar serta nama tempat pasien berada saat ini. Kedua, menggunakan deret angka dengan cara menghitung maju atau mundur. Ketiga yaitu dengan teknik tujuh serial, teknik ini digunakan untuk menilai kemampuan untuk mengurangi tujuh secara berulang dari angka 100, atau jika gagal menjawab, menghitung mundur dari 20, atau menyebutkan nama bulan dalam setahun dengan urutan terbalik. ${ }^{8}$ Dari beberapa teknik diatas bisa diaplikasikan untuk menilai seberapa besar nilai disorientasi yang dialami oleh pasien, sehingga peneliti akan mudah untuk mengelompokkan apakah pasien tersebut masuk kedalam kategori disorientasi ringan, disorientasi sedang atau bahkan masuk dalam kategori disorientasi berat.

\section{Hubungan Cedera Kepala dengan Disorientasi Pada Pasien Kecelakaan Lalu Lintas di RSD Gunung Jati Kota Cirebon}

Hasil penelitian tersebut terbukti dan diterima melalui uji dengan Khi Kuadrat, dengan tingkat kesalahan 5\% atau tingkat kepercayaan 95\% didapatkan nilai probabiliti ( $p$ value) 0,006 atau lebih kecil dari alpa $(0,05)$ sehingga dengan demikian hipotesis alternatif diterima (Ho ditolak) yaitu ada terdapat hubungan antara cederakepala dengan disorientasi pada pasien kecelakaan lalu lintas di RSUD Gunung Jati Kota.

Cedera kepala adalah suatu gangguan traumatik dari fungsi otak yang disertai perdarahan interstiil dalam substansi otak tanpa diikuti terputusnya kontinuitas otak. ${ }^{9}$ Senada dengan pernyataan tersebut cedera kepala adalah suatu ruda paksa (trauma) yang menimpa struktur kepala sehingga dapat menimbulkan kelainan struktural dan atau gangguan fungsional jaringan otak. ${ }^{10}$

Otak dapat berfungsi dengan baik bila kebutuhan oksigen dan glukosa dapat terpenuhi. Energi yang dihasilkan didalam sel-sel saraf hampir seluruhnya melalui proses oksidasi. Otak tidak mempunyai cadangan oksigen, jadi kekurangan aliran darah keotak walaupun sebentar akan menyebabkan gangguan fungsi. Demikian pula dengan kebutuhan oksigen sebagai bahan bakar metabolisme otak tidak boleh kurang dari $20 \mathrm{mg} \%$, karena akan menimbulkan koma. Kebutuhan glukosa sebanyak $25 \%$ dari seluruh kebutuhan glukosa tubuh, sehingga bila kadar glukosa plasma turun sampai $70 \%$ akan terjadi gejala-gejala permulaan disfungsi cerebral. ${ }^{10}$ Pada saaat otak mengalami hipoksia, tubuh berusaha memenuhi kebutuhan oksigen melalui proses metabolik 
anaerob yang dapat menyebabkan dilatasi pembuluh darah. Pada kontusio berat, hipoksia atau kerusakan otak akan terjadi penimbunan asam laktat akibat metabolisme anaerob. Hal ini akan menyebabkan asidosis metabolik. ${ }^{10}$

Pada setiap kategori, respons yang terbaik diberikan nilai. Nilai total maksimum untuk sadar penuh dan terjaga adalah 15 . Nilai minimum 3 menandakan klien tidak memberikan respons. Jika nilai keseluruhan 8 atau dibawahnya, klien dinyatakan koma. Jika nilai tersebut bertahan selama waktu yang lama mungkin hal ini menjadi salah satu indikator buruknya pemulihan fungsi. Sistem penilaian ini dirancang sebagai pedoman untuk melakukan evaluasi dengan cepat pada klien yang sakit kritis atau klien yang cedera sangat berat yang memiliki status kesehatan yang dapat berubah dengan cepat. ${ }^{11}$

Hasil penelitian Trisnawati Habibie (2017) menunjukan hasil penelitiannya bahwa terdapat hubungan cedera kepala dengan disorientasi pada pasien kecelakaan lalu lintas. pasien cedera mengalami disorientasi orang, waktu dan tempat. Tingkat kesadaran TTV dan respon motorik maupun pupil semuanya dalam rentang normal. Namun tatapannya tidak fokus hingga dicurigai dapat mempengaruhi neurologisnya. Dapat dilihat bahwa cedera kepala dapat mempengaruhi orientasi dan neurologis pasien jika tidak segera di tindak lanjuti oleh tenaga medis. ${ }^{12}$

\section{SIMPULAN}

1. Sebagian besar kecelakaan lalu lintas cedera kepala di RSD Gunung Jati Kota Cirebon yaitu cedera kepala ringan sebanyak 16 responden $(72,7 \%)$.

2. Sebagian besar kecelakaan lalu lintas cedera kepala di RSD Gunung Jati Kota Cirebon mengalami disorientasi sedang sebanyak 14 responden $(63,6 \%)$.

3. Ada hubungan antara cedera kepala dengan disorientasi pada pasien kecelakaan lalu lintas di RSD Gunung Jati Kota Cirebon dengan nilai (pvalue 0.001)

\section{SARAN}

1. Bagi Perawat IGD, sebaiknya untuk pasien gawat darurat seperti pasien cedera kepala agar mendapatkan penanganan yang tepat agar tidak terjadi disorientasi dan mendapat pelayanan waktu tanggap yang baik dari perawat sehingga mendapatkan peningkatan kesehatan.

2. Bagi Rumah Sakit, hasil penelitian ini diharapkan dapat memberikan informasi tentang hubungan cedera kepala dengan disorientasi pada pasien kecelakaan lalu lintas, sehingga dapat menjadi bahan masukan dan guna untuk meningkatkan derajat kesehatan.

3. Bagi Responden, diharapkan responden untuk meningkatkan kesadaran diri saat berkendara agar berhati hati dalam mengendarai kendaraan dan menjaga keamanan agar tidak terjadi kecelakaan lalu lintas yang menyebabkan cedera kepala.

\section{DAFTAR PUSTAKA}

1. Depkes RI. Kasus kecelakaan lalu lintas di indonesia pada tahun 2013 [Diakses tanggal 20 Oktober 2017] Diunduh dari: http://www.depkes.go.id/

2. Damanik, R. P. Karakteristik Penderita Cedera Kepala Akibat Kecelekaan Lalu H. Kumpulan Pane Tebing Tinggi Tahun 2011. [Diakses tanggal, 23 Oktober 2017]. Diunduh dari: http://repository.usu.ac.id/

3. Depkes RI. Kasus cedera kepala di indonesia pada tahun 2013 [Diakses pada tanggal 23 Oktober 2017] Diunduh dari: http://www.depkes.go.id/

4. Abu Albani. Disorientasi Pemikiran. [Diakses pada tanggal 23 Oktober 2017] Diunduh dari: http://www.abualbanicentre.com/artikel/disorientasi-pemikiran/

5. .Medical Record IGD RSD Gunung Jati Kota Cirebon dan IGD Rumah Sakit Tk. 111 03.06.01 Ciremai; 2017

6. A. Azis Alimu H. Metode Penelitian Keperawatan dan Teknik Analisa Data. Jakarta: Salemba Medika; 2007 
7. Wiratna Sujarweni. Metodologi Penelitian Keperawatan. Yogyakarta: Penerbit Gava Media; 2014

8. Lionel Ginsberg. Lecture Notes: Neurologi. Jakarta: Erlangga Medical Series; 2008.

9. Padila. Buku Ajar: Keperawatan Medikal Bedah. Yogyakarta. Nuha Medika; 2012

10. Sastrodiningrat, A.G. Memahami faktor-faktor yang mempengaruhi prognosa cedera kepala berat. Majalah Kedokteran Nusantara; 2009

11. Arif Muttaqin. Pengantar Asuhan Keperawatan Klien dengan Gangguan Sistem Persarafan. Jakarta: Salemba Medika; 2008.

12. Trisnawati Habibie, Hendro Bidjuni, Reginus T. Malara. Hubungan cedera kepala dengan disorientasi pada pasien kecelakaan lalu lintas di IGD RS Bhayangkara Manado Tahun 2017. [Diakses pada tanggal 24 Oktober 2017]. Diunduh dari: https://ejournal.unsrat.ac.id 